\title{
The Influence of Zr on Microstructure, Mechanical Properties and Corrosion Resistance in Mg-Y-Zr Biodegradable Alloys
}

\author{
STEFAN LUPESCUㄹ, CORNELIU MUNTEANU ${ }^{1}$, BOGDAN ISTRATE ${ }^{1 *}$, KAMEL EARAR ${ }^{2}$ \\ ${ }^{1}$ Gheorghe Asachi University of lasi, Mechanical Engineering Department, 6 D. Mangeron Blvd, 700050, lasi, Romania \\ 2Dunarea de J os University of Galati, Faculty of Medicine, Dental Medicine, Al. I. Cuza 35 Str., 800010, Galati, Romania
}

\begin{abstract}
The latest magnesium alloys are widely used in the medical field, especially for biodegradable implants. Magnesium alloys are very attractive for applications in different structures in the automotive, aerospace, printing and even medical fields [1]. It should be noted that some magnesium alloys have excellent damping properties as well as good mechanical properties, making them promising to respond to high damping needs for vibration control [1,2]. Although widely used, magnesium has a low corrosion resistance. To improve this resistance, different types of magnesium based on aluminum, such as Ca, Mn, Zn, Zr, Si and rare rare $(Y, G d$..), can be developed. The main purpose of this paper is to investigate the properties of a primary alloy based on the Mg-1Y-0,5Zr system with different concentrations of $\operatorname{Zr}(0.5,1,2)$ used in the development of alloys based on the biodegradability of $M g$. Surface morphology was characterized by electronic scanning microscopy (SEM), X-ray diffraction (XRD) and optical microscopy. After XRD analysis, it was observed that certain specific compounds were made up of Mg2Ca, MgZr, Mg2Y, Mg24Y5 having the main Mg formed in the hexagonal structure, but Mg24Y5 are the cubic crystalline structure. Also, the microhardness of the alloy is higher than pure $\mathrm{Mg}$ and the scratch mark is smaller than that of pure $\mathrm{Mg}$. The corrosion resistance was developed using linear voltammetry in specific medium and corrosion showed that it had significantly decreased for masteralloy. As a final conclusion, the structural properties of this model are recommended for use as medical implants.
\end{abstract}

Keywords: Micro-Hardness, SEM, XRD, optical microstructure

Mg alloys have gained a lot of interest over the past few years in various fields such as automotive, medical, aerospace industries due to their low density, good casting capacity and higher specific strength. [1, 4] For medical implants, it has been shown that $\mathrm{Mg}$ is a modulus of elasticity comparable to that of the cortical bone, eliminating the stress protection elements that may occur due to a impediment of a module betw een the implanted material and the bone. [2] Mg-based implants have been show $n$ to have a better osteointegration at the bone-implant interface compared to Ti-based alloys. [3] In addition to these significant advantages, it has also been shown to be disadvantages by low strength and high rate of degradation, which are major obstacles to the use of $\mathrm{Mg}$ in medical applications, as they can lead to the loss of structural integrity and the elimination of toxic substances before the tissue is fully cured [18].

Similarly, although Li has been used in medicine for nearly 150 years [16, 17], it has not been widely used in implanted materials where a continuous exposure of $\mathrm{mg}$ per day can occur [18]. In over the last decade significant research has been carried out on Mg-based alloys to eliminate as many disadvantages as possible. Pure $\mathrm{Mg}$ is unable to provide the necessary mechanical properties [13, 14] and corrosion resistance [15] required for a wide variety of implant applications. Therefore, potential alloying elements should be carefully considered. Alloying Mg with various elements such as Al, $\mathrm{Zn}, \mathrm{Ca}, \mathrm{RE}$, and others has been proven to improve mechanical properties and reduce the rate of degradation of $\mathrm{Mg}$. [6-12] The addition of $Y$ (Yttrium) has been used in $\mathrm{Mg}$ alloys for biodegradable applications due to its beneficial effect on corrosion and resistance of $\mathrm{Mg}$ alloys as well as the lack of toxicity at normal alloying concentration. $[7,8]$ It is demonstrated that $Y 203$ has high thermodynamic stability and has been shown to reduce the rate of degradation of Mg-based alloys. [7-9] $\mathrm{Zr}$ also reduces the rate of degradation over time.

Based on these considerations, this paper seeks to investigate the mechanical properties of the Mg-Zr-Y alloy with different concentrations of $\operatorname{Zr}(0.5,1,2)$ to make a comparison between the properties of the 3 recipes and decide which one is the most indicated for medical applications.

\section{Experimental part \\ Materials and methods}

Alloys based on Mg: B1(Mg-1Y-0.5Zr), B2(Mg-1Y-1Zr), $\mathrm{B} 3(\mathrm{Mg}-1 \mathrm{Y}-2 \mathrm{Zr})$ were prepared in molds of graphite crucibles and homogenized at 700 degrees Celsius for 3 hours in an induction furnace under the protection of an inert atmosphere ( $\mathrm{Ar})$. This operation was repeated in all three samples. Samples were cut to sizes $7-8 \mathrm{~mm} \times 10 \mathrm{~mm}$, polished primarily with abrasive paper with grains of 150 to $1000 \mathrm{SiC}$, then cleaned with pure ethanol and dried in free air before being worked out. After elaboration, the ingots were cut into pills with a diameter of about $15 \mathrm{~mm}$ and a thickness of $5 \mathrm{~mm}$. The samples were sanded with abrasive paper with a grain size of up to $2000 \mathrm{SiC}$ to obtain a uniform surface. The analyzed surface of each sample was milled and polished to a final finish with a $0.05 \mu \mathrm{m}$ alumina suspension.

Prior to observation, the samples were etched using 4\% w / w nitric acid in ethanol for 5-8 s, thoroughly washed with water and alcohol and then dried with hot air. The morphology and alloy microstructure was determined using a double BSD (backscatter) LFD (double field detector) with a SEM Quanta 2003 D DUAL BEAM electronic scanning microscope. For phase analysis, XRD analysis was 


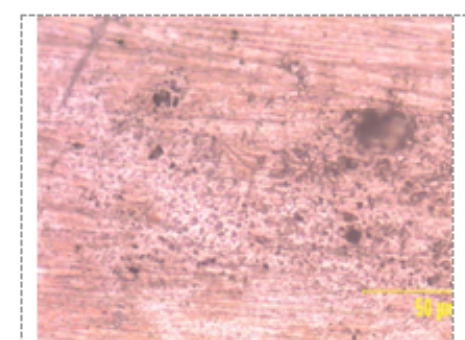

a) $\mathrm{Mg}-1 \mathrm{Y}-0.5 \mathrm{Zr}$

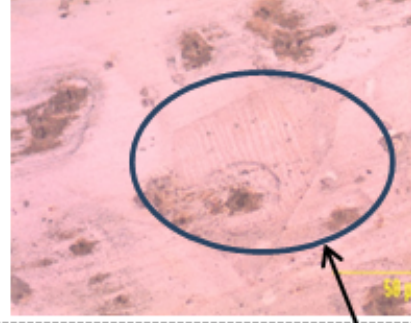

b) $\mathrm{Mg}-1 \mathrm{Y}-1 \mathrm{Zr}$

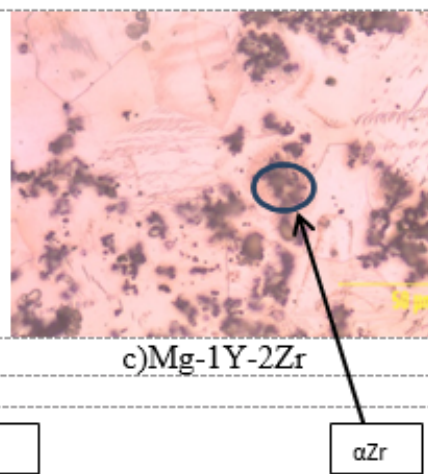

$\alpha \mathrm{Zr}$
Fig.1 Optical analysis of the material performed using an X'Pert Pro MPD diffractometer, with acopper X-ray tube of Cu: $1.54 \mathrm{~A}$ in the $2^{\circ} \mathrm{T}$ scan range of $20^{\circ}-90^{\circ}$. The apparent coefficient of friction, hardness and modulus of elasticity were measured using the CETR UMT-2

Tribumer. Parameters of micro-scratch analysis: a constant load of $5 \mathrm{~N}$ at a distance of $4 \mathrm{~mm}$, for a single determination, on a sample probe of $25 \mathrm{~mm} \times 7 \mathrm{~mm}$. The indentations were also made 3 determinations for each sample with a loading $5 \mathrm{~N}$ using a metal indenter.

\section{Results and discussions}

Structural analysis

Optical images

The images shown below represent the morphology of the analyzed sample area, captured at the Leica 5000DMI microscope at a magnification of 500x and shows the influence of $\mathrm{Zr}$ and its quantity. It is noted in figure $1 b$ the grains of Mg have larger dimensions and after increasing the content of $Z r$, microstructure is refined (fig. 1c).

The structure is observed to be homogeneous and free of cracks within the alloy.

\section{Scanning electron microscopy.}

Microstructural and morphological aspects of Mg-Y-Zr prealloys with different concentrations of $\mathrm{Zr}$ are shown in figure 2 (a-c). It is possible to observe the specific aspects of each prealloys. The images captured at different zoom scales show the increase in the amount of Zr which leads to refining the microstructure. Also, in figure 2 (a) we can see the Mg-1Y-0.5Zr alloy of Mg grains compared to figure 2 (c) in which the microstructure of the Mg-1Y-2Zr alloy is presented, significant zirconium content being observed. The grains formed after casting these four alloys have different shapes depending on the alloy that predominates in a certain area.

\section{$X R D$ analysis}

The XRD analysis was performed on a Panalytical XPERT Pro MPD diffractometer, CuK $\alpha$ X-ray. The XRD models are shown in figure 3, Pure Magnesium is highlighted at 33.46p (2Theta - as the highest peak). There were highlighted the compounds for Bl $\alpha Z$ r having the cubic crystallographic structure, and $\mathrm{Mg}, \mathrm{Mg} 2 \mathrm{Y}, \mathrm{Y}$ having the hexagonal crystallographic structure. For the B2 alloy of the following compounds, Y having the cubic crystallographic structure, and the $\alpha Z r, M g, M g 2 Y$ having the hexagonal structure, were revealed. And for the 3rd B3 alloy we have 2 compounds with a cubic crystallographic structure (Mg24Y5 and $Y$ ) and $\alpha Z r$, Mg together with inco a $Y$ form a hexagonal crystallographic structure. Parameters of all compounds are shown in table 1.

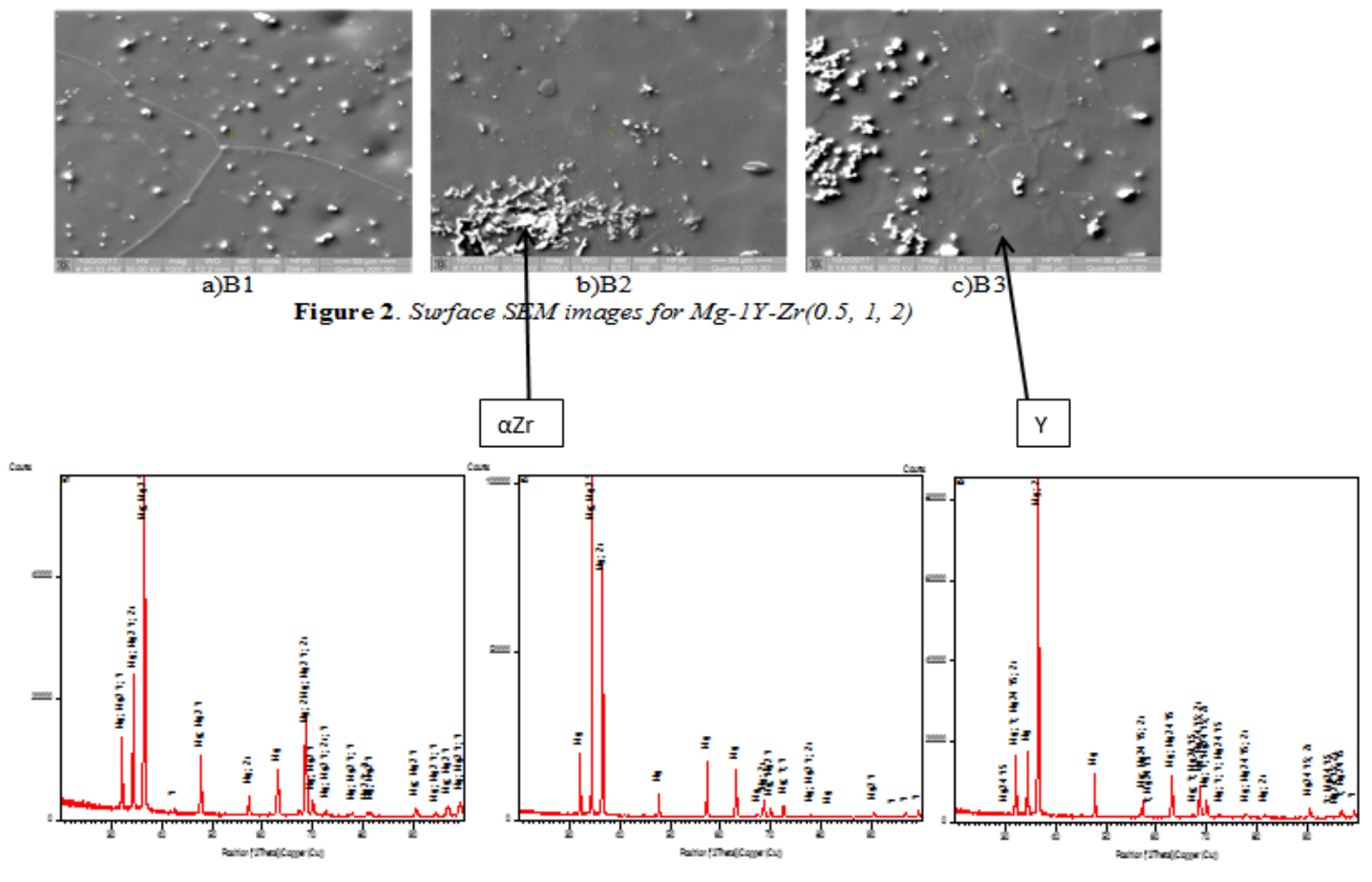

Fig. 3 XRD Diffraction: (a) B1(Mg-1Y-0.5Zr), (b) B2(Mg-1Y-1Zr), (c) B3(Mg-1Y-2Zr) 
Table 1

LATTICE PARAMETERS of Mg-Y-Zr ALLOYS

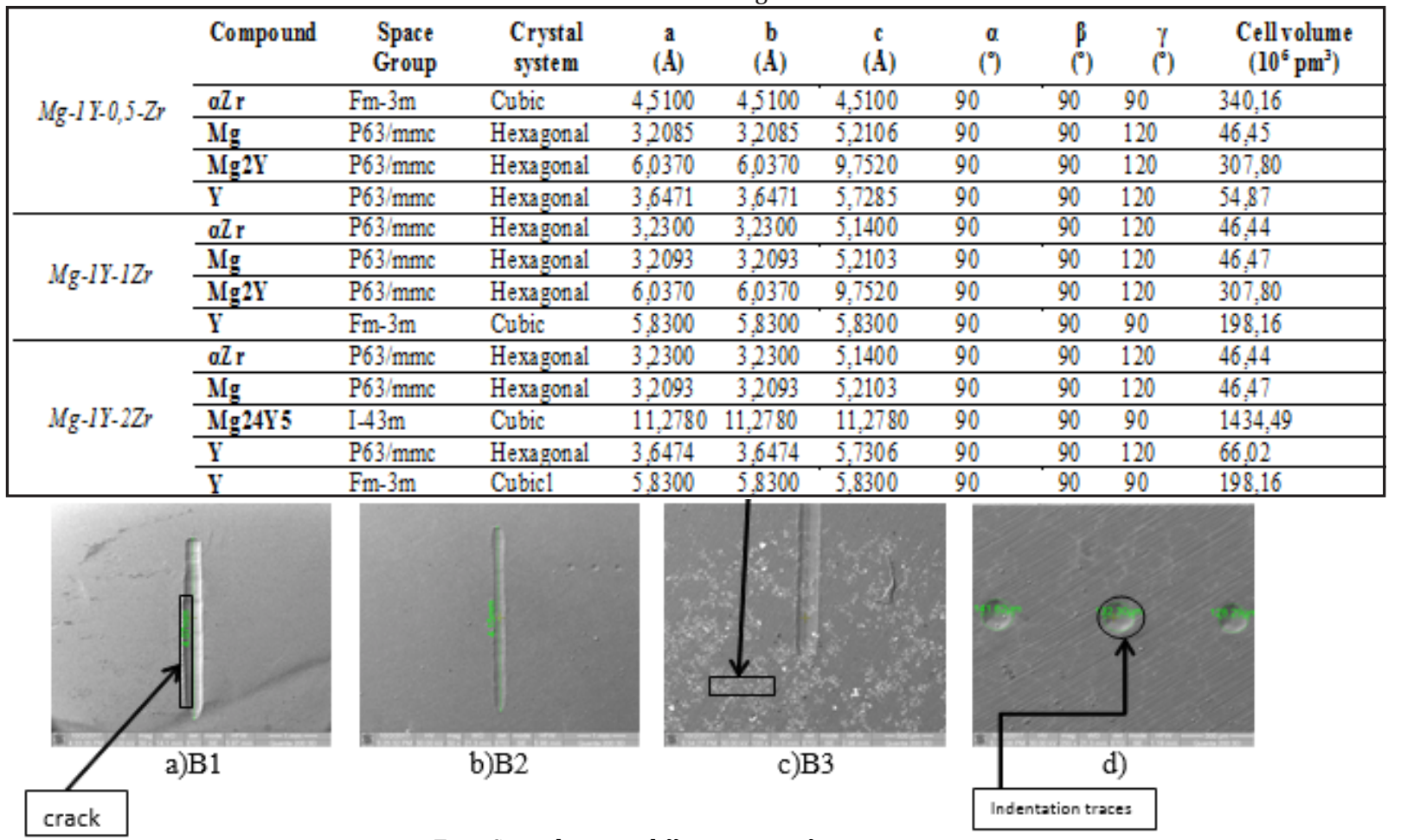

Fig.4 Scratching on different magnifying powers

\begin{tabular}{|c|c|c|c|}
\hline$M g-2 C a-0,2 M n-0,5 Z r-1 Y$ & $\overrightarrow{B 1}$ & $B 2$ & B3 \\
\hline $\operatorname{Detph}[\mu \mathrm{m}]$ & 18.65 & 11.17 & 8.64 \\
\hline Stiffness [N/ $/ \mu \mathrm{m}]$ & 1.37 & 2.11 & 3.19 \\
\hline Young mochulus [GPa] & 8.33 & 16.56 & 28.48 \\
\hline COF & 1.21 & 0.46 & 0.44 \\
\hline Hordness [GPa] & 0.22 & 0.38 & 0.48 \\
\hline Load & 4.46 & 4.51 & 4.52 \\
\hline
\end{tabular}

Table 2

SOME MECHANICAL PROPERTIES OF B1(Mg-1Y-0.5Zr), B2(Mg-1Y-1Zr), $B 3(M g-1 Y-2 Z r)$
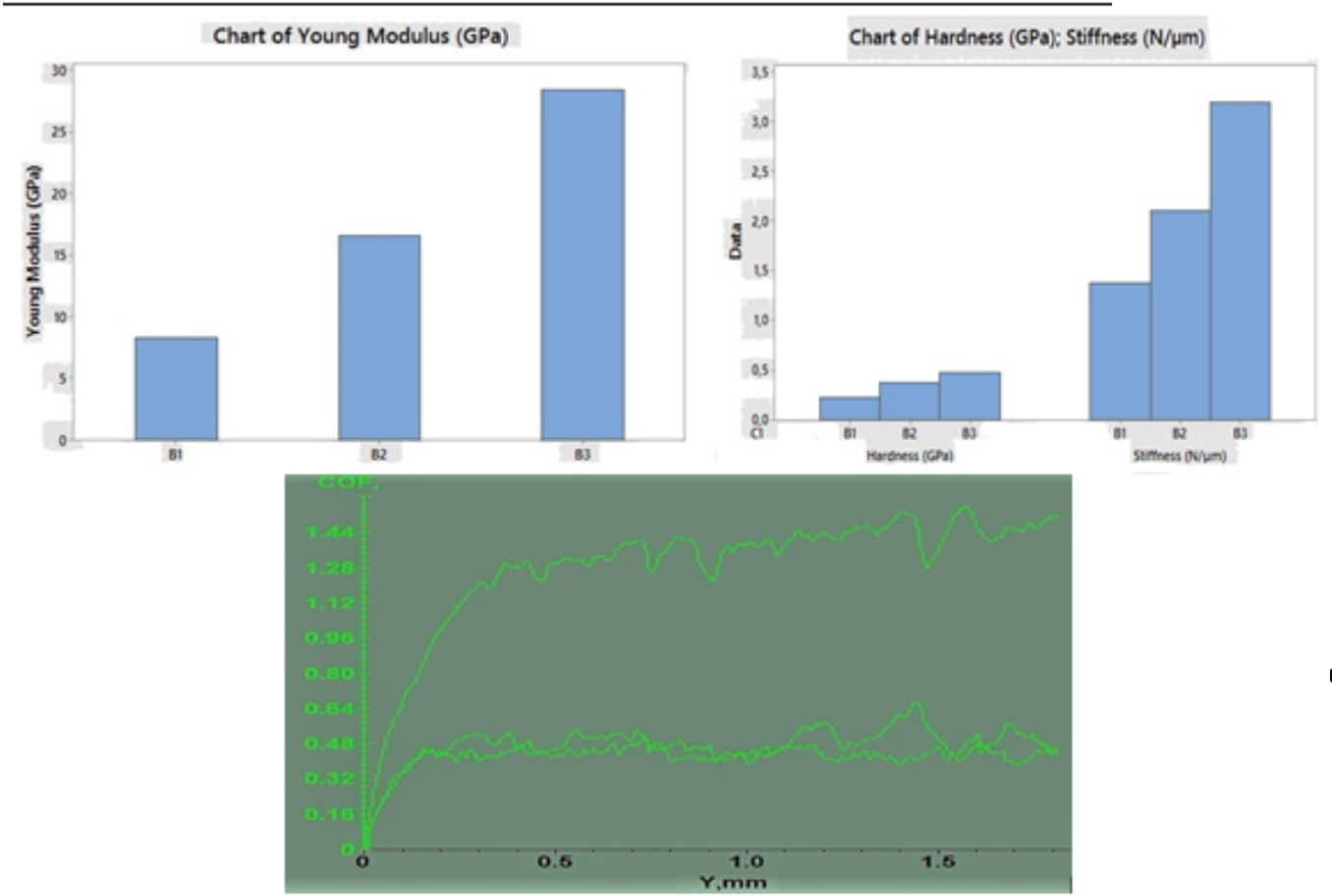

Fig. 4a) Determination of the Young modulus parameters for the 3 alloys; b) Comparative graph for the 2 powders used with the obtained parameters following the microscratch process; c) Graph coefficient of friction

Scratch and micro-indentation analysis.

Figure 4 shows the scratch marks $(a, b, c)$ and in figure $4 \mathrm{~d}$ the traces after the indentation test. Figure 4a shows a rupture of material which shows that the alloy $B 1$ is softer compared to the alloy B3 in figure $4 C$, where there is the largest amount of $\mathrm{Zr}$ and the increase of stiffness is observed. Table 2 shows the values for the Young module, the hardness, the scratch, the friction coefficient and the stiffness for all three tests. 


\section{Conclusions}

This study made a comparison between the B1 alloy (with a low $\mathrm{Zr}$ content) and the $\mathrm{Zr}$ influence with the increase of its content and the benefits of refining the microstructure, increasing the alloy's hardness over 2 times, increasing the elastic modulus by almost 4 times and decreasing the friction coefficient. Or found different compounds with different cubic and hexagonal structure. The scrach test showed a material breakage at alloy B1, which shows that the material is softer being even poorer alloyed (lower Zr content). Butat alloy B3 (high Zr content) penetration into material is 2 times smaller than to B1 alloy.

Acknowledgements:This work was supported by a grant of the Romanian Ministery of Research and Innovation, CCCDI - UEFISCDI, projectnumberPN-III-P1-1.2-PCCDI-2017-0239/60PCCDI 2018, within PNCDI III.

\section{References}

1.LUPESCU, S., ISTRATE, B., MUNTEANU, C., MINCIUNA, M.G., FOCSANEANU, S., EARAR, K. Characterization of Some Master Mg-X System ( $\mathrm{Ca}, \mathrm{Mn}, \mathrm{Zr}, \mathrm{Y})$ alloys used in medical applications, Rev.Chim.(Bucharest), 68, no.6, 2017, p.1408-1413

2. S. SHRESTHA, Magnesium and surface engineering, Surf. Eng. 26 (2010)313-316.

3.BITA, A.I., ANTONIAC, A., COTRUT, C., VASILE, E., CIUCA, I., NICULESCU, M. ANTONIAC, I., In vitro degradation and corrosion evaluation of Mg-Ca alloys for biomedical applications Journal of Optoelectronics and Advanced Materials Volume 18, Issue 3-4, MarchApril 2016, Pages 394-398

4. BALTATU, M.S., VIZUREANU, P., BENCHEA, M., MINCIUNA, M.G., ACHITEI, D.C., ISTRATE, B., Ti-Mo-Zr-Ta alloy for biomedical applications: Microstructures and mechanical properties Key Engineering Materials Volume 750 KEM, 2017, Pages 184-188

5. STAIGER MP, PIETAK AM, HUADMAI J, DIAS G. Magnesium and its alloys as orthopedic biomaterials: a review. Biomaterials 2006;27:172834.
6..B.L. MORDIKE, T. EBERT, Magnesium: properties-applicationspotential, Mater.Sci. Eng. A 302 (2001) 37-45.

7. WITTE F, HORT N, VOGT C, COHEN S, KAINER KU, WILLUMEIT R, et al. Degradable biomaterials based on magnesium corrosion. Curr Opin Solid State Mater Sci 2008;12:63-72.

8. HANZI AC, GUNDE P, SCHINHAMMER M, UGGOWITZER PJ. On the biodegradation performance of an Mg-Y-RE alloy with various surface conditions in simulated body fluid. Acta Biomater 2009;5:162-71.

9..SOCJ USZ-PODOSEK M, LITYNSKA L. Effect of yttrium on structure and mechanical properties of Mg alloys. Mater Chem Phys 2003;80:4725 .

10. LIU M, SCHMUTZ P, UGGOWITZER PJ, SONG G, ATRENS A. The influence of yttrium $(Y) n$ the corrosion of $M g-Y$ binary alloys. Corros Sci 2010;52:3687-701.

11. XU LP, YU GN, ZHANG E, PAN F, YANG K. In vivo corrosion behavior of $\mathrm{Mg}-\mathrm{Mn}$-Zn alloy for bone implant application. J Biomed Mater Res 2007;83A:703-11.

12.VOJTECH, D.,. CIZOVA, H., VOLENEC,K., Investigation of magnesium-based alloys for biomedical applications, Kovove Mater, 2006(44), 211-223.

13. GANESHAN, S., SHANG,S.L., WANG, Y., LIU,Z.K., Effect of alloying elements on the elastic properties of $\mathrm{Mg}$ from first-principles calculations, ActaMaterialia, 2009, 57(13), 3876-3884.

14. KIRKLAND, N.T., LESPAGNOL, J., BIRBILIS, N., STAIGER,M.P., A Survey of Bio-Corrosion Rates of Magnesium Alloys', Corrosion Science, 2010, 52(2), 287-291.

15. TIMMER , R.T., SANDS, J.M., Lithium Intoxication, J Am SocNephrol, 1999, 10(3), 666674.

16. BHAGWAGAR , Z., GOODWIN, G.M., The role of lithium in the treatment of bipolar depression', Clinical Neuroscience Research, 2002, 2(3-4), 222-227.

17. YFANTIS, C.D.,YFANTIS, D.K.,ANASTASSOPOULOU, J., THEOPHANIDES, T., STAIGER,M.P., New magnesium alloys for bone tissue engineering: in vitro corrosion testing, WSEAS transactions on Environment and Development, 2006, 2(8), 1110-1115.

Manuscript received: 03.08 .2018 